\title{
Coletividade e destruição: relato de um processo
}

Collectivity and destruction: report of a process

\section{Alexandre Ferreira Dal Farra Martins}

Alexandre Ferreira Dal Farra Martins Doutorando do Programa de Pós-Graduação em Artes Cênicas da Escola de Comunicações e Artes da Universidade de São Paulo (USP).

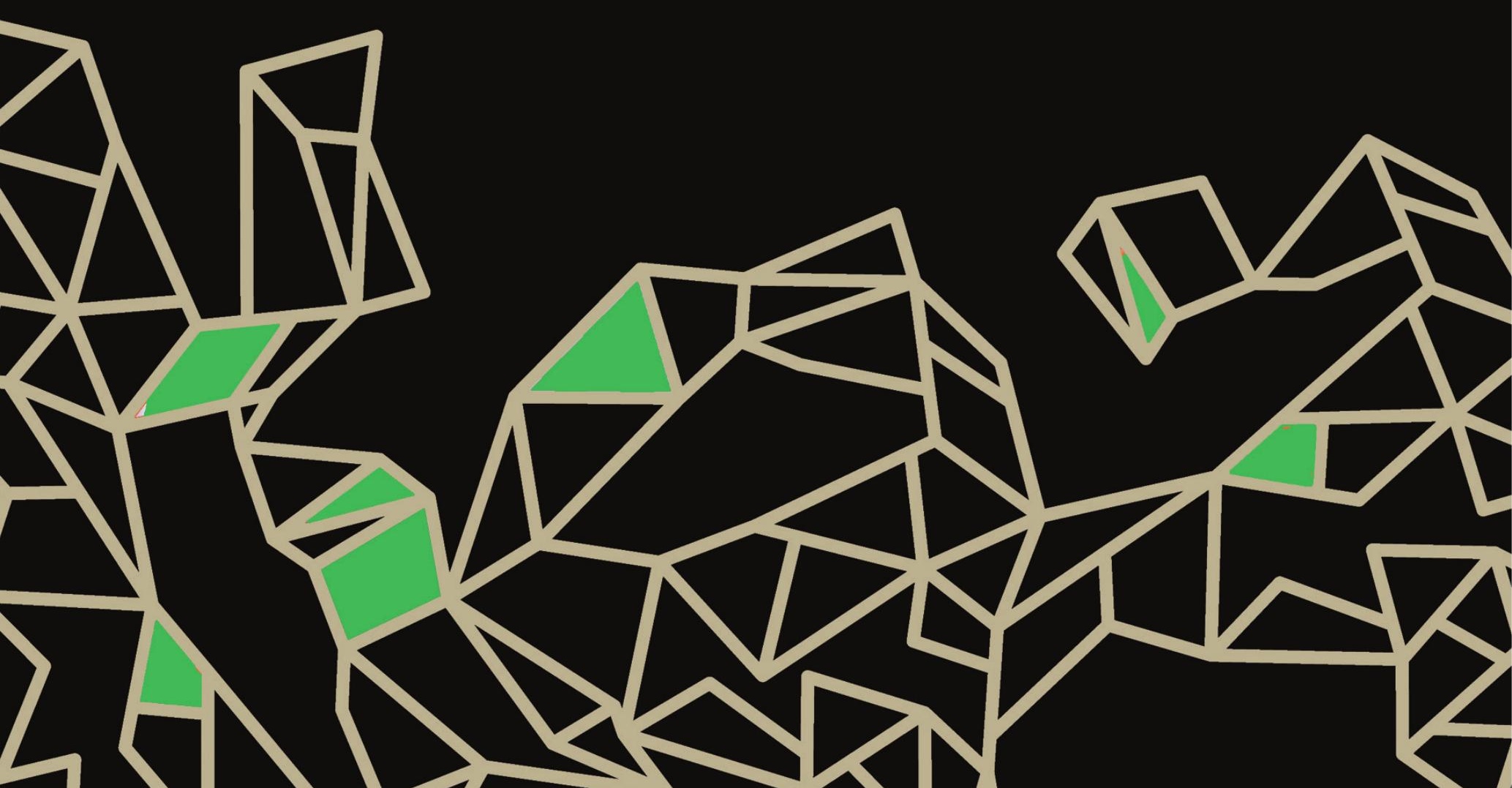




\section{Resumo}

O autor Alexandre Dal Farra procura entender o processo de criação de Branco: o cheiro do lírio e do formol a partir de um olhar sobre as possibilidades que o trabalho, a partir de uma postura destrutiva, oferece em termos de uma criação coletiva - ainda que com funções claramente determinadas. $\mathrm{O}$ impulso destrutivo ou profanatório aparece como possibilidade de ação fraterna e capaz de unir.

Palavras-chave: Destrutividade, Coletividade, Teatro Aformativo.

\section{Abstract}

The author Alexandre Dal Farra seeks to understand the process of creation of Branco: o cheiro do lírio e do formol (White: the smell of lily and formaldehyde), from a gaze at the possibilities that the work with a destructive posture offers in terms of a collective creation - still with clearly defined functions. Destructive or defiling impulse appears as a possibility of fraternal action and capable of uniting.

Keywords: Destructiveness, Collectivity, Aformative Theater.

Foi difícil chegar a uma proposta para a escrita deste texto sobre Branco: o cheiro do lírio e do formol. Talvez por se tratar de uma experiência muito intensa, para mim não foi simples encontrar uma forma de falar sobre esta peça - o que não deixa de ser o sinal de que há algo nela de perturbador que por si só me interessa. Nunca quis fazer um teatro que eu soubesse falar sobre, que eu dominasse, e tendo a desconfiar de ideias teatrais e artísticas cujas intenções e proposições eu saiba explicar. Me interessa a arte que justamente não se traduz em nada, que toca em coisas que só ela pode tocar, que dissolve o que se pretende falar sobre ela. Acho que Branco tem essa capacidade.

Trata-se de uma peça que teve, no entanto, uma peculiaridade no seu processo que cabe expor. Foi um processo que, por um lado, teve como principal território o da escrita - com efeito, o primeiro ponto de partida da peça foi um texto que já estava finalizado antes de tudo, e depois foram escritos mais dois textos inteiros - sendo que o terceiro é a peça. Ou seja, foi um processo muito intenso de escrita, pautado na construção de uma dramaturgia 
que depois se transformou em cena - só entramos em sala de ensaio depois de que o terceiro texto estava totalmente pronto. Esse movimento de escrita, reescrita, de elaborar um texto, mostrá-lo, voltar com ele para casa, reescrevê-lo, jogá-lo inteiramente fora, foi basicamente o gesto de construção da peça.

Tal processo, no entanto, se deu de uma forma que foi, simultaneamente, bastante coletiva. Não na construção do texto em si, mas na construção da peça como um todo, no seu gesto. Houve um engajamento, um envolvimento, por parte dos parceiros André Capuano, Clayton Mariano e Janaina Leite, sem o qual não seria possível a peça existir. Ela exigia de todos nós um grau e um tipo de envolvimento muito específico, que implicava risco, o prazer de se mover, de se modificar, de sair do seu lugar de conforto. Em um primeiro momento, eu tinha apenas um texto. Entretanto, já de cara estava entranhada na própria escrita um movimento de autodestruição, autodiluição, que depois só se aprofundou, e assim já era bastante claro que para esse trabalho seria necessário convidar atores que fossem capazes de mergulhar em tal movimento, que também tivessem, neles mesmos, uma espécie de desejo e de prazer em fazê-lo. Quando os convites foram feitos, invariavelmente, a vontade de fazer parte do projeto envolvia já essa vontade - de se mover, de se alterar, de destruir coisas dentro de si mesmos.

Tenho para mim que uma das formas de colaboração mais profundas e mais fraternas é a colaboração na destruição. A colaboração na construção por vezes tende a se dissipar em disputas de território, ou, quando isso não ocorre, pode-se instalar um tipo de diplomacia bem-comportada. Quando, ao contrário, os laços que nos unem são impulsos destrutivos, parece que não há espaço para questões menores. É preciso coragem, no entanto, para sair de um lugar hoje absolutamente dominante, onde todos só se preocupam constantemente com o modo como suas ações serão vistas pelos outros e a arte se transforma em um instrumento para que mostrem as suas opiniões para os outros. Existe uma fraternidade incrivelmente grandiosa nos movimentos de autodestruição. Como, em Branco, o nosso desejo e, penso eu, o que efetivamente conseguimos com a peça, era um caminho de autodestruição daquilo que, em nós, é opressor, nunca entramos em discussões acerca do que a peça queria ou não dizer, ou do que seria lido da peça. Porque nunca interessou a forma como a peça seria lida. Só se preocupa com a forma como 
algo será lido aquele que quer "passar algo" por meio da peça - aquele que se utiliza da peça como um meio para determinados fins. Nós não queríamos, todavia, "passar" nada com a peça. Nós queríamos aniquilar coisas. E no caso da aniquilação, ela não precisa ser transmitida ou explicada e não se dirige a algo externo a ela própria. Ao contrário, ela simplesmente se dá. O público é testemunha e, evidentemente, pode inclusive não querer vê-la. Falando sobre o seu Saló, Pasolini disse certa vez que ser escandalizado é um prazer, e que só não desfruta desse prazer o moralista, ou seja, aquele que está apegado demais às suas posições morais, de tal forma que não consegue se atirar no prazer de alterá-las. Creio que se dá o mesmo no caso de toda obra destrutiva. Não acho que o Branco escandalize. Mas ele dissolve, deforma, se autodilui através de um processo de derretimento das camadas da peça umas contra as outras. Também a autodiluição é um prazer, me parece. Não para todos. Para aqueles que estão apegados demais às suas posições, ao seu discurso, esse movimento destrutivo, diluidor, pode ser mesmo doloroso demais e mesmo impossível.

Isso foi algo determinante e absolutamente estruturador para o processo de criação do Branco, que nós estivéssemos juntos nesse movimento único que é maior que cada um de nós, e que nos une, que é o movimento da dissolução e da autodestruição de estruturas internas nossas. A falta de necessidade de afirmar nos unia com muito mais fraternidade porque não precisávamos entrar nas cansativas discussões sobre o que queríamos afinal dizer com aquilo tudo. Observando ultimamente as dificuldades de diversos coletivos - alguns de que fiz parte, outros não - em processos cuja linha mestra é a afirmação de posições, creio que posso dizer que a afirmação se tornou contraditoriamente um fator de enfraquecimento do coletivo. Hoje, o coletivo só se faz possível na destruição, na "aformação". Assim que a afirmação se coloca, instaura-se a diferença, a divisão. Não à toa o Facebook não tem um botão de "não curti". O algoritmo sabe que a melhor forma de mapear os indivíduos e dividi-los em grupos cada vez menores (com o intuito, obviamente, de fornecer ferramentas mais e mais precisas de marketing) é saber o que as pessoas afirmam. As pessoas se dividem em grupos segundo o que elas afirmam - e o que elas negam, quando negam, precisa ser sempre transformado em negativo daquilo que é afirmado por outro lado. 
A potência da destruição como força pura, que não aponta para nenhuma afirmação como contrapartida, não permite mapear os desejos e não permite, portanto, que se perpetue a imensa pesquisa de marketing que se tornaram as nossas vidas - por meio da mediação das mídias sociais. A união na destruição se retira totalmente de toda essa lógica e, sem simplesmente se preocupar com ela, se instaura enquanto movimento que não tem como ser individual.

Creio que é por conta disso que se cria uma voz em primeira pessoa, na peça, que se dissolve em todos os que falam. Essa primeira pessoa não importa. Importa o que é feito com ela. O "eu" não está ali para se afirmar, mas para ser aniquilado. $O$ processo da peça foi efetivamente o processo dessa aniquilação - e, como tal, profundamente coletivo.

Já no final do processo, faltando menos de dois meses para a estreia da peça, me lembro que nos reunimos e eu disse aos outros que achava que a peça não era nada daquilo, que o texto (era então já o segundo texto) precisava também (assim como o primeiro o fora) ser jogado inteiramente fora, e que eu escreveria um texto inteiramente novo. Obviamente um dos meus medos à altura era que houvesse resistência a essa postura um tanto quanto "camicase" - depois de tantas reescritas, de tantas conversas, de tantas decisões, jogar tudo fora poderia parecer uma loucura. No entanto, isso não passou nem perto de acontecer, e novamente me lembrei da importância de se estar com os parceiros certos. O impulso destrutivo novamente se instaurou inapelavelmente, e a perspectiva foi amplamente aceita, com muito gosto, aliás, pela perspectiva de poder mover tudo de novo, de, ainda mais uma vez, alterar tudo. Sempre me orgulhei silenciosamente da minha capacidade de jogar coisas fora, de me desvencilhar de cenas, textos, propostas. Tal forma de trabalhar, que também pode ser pensada como destrutiva, demanda, contudo, a parceria de pessoas igualmente capazes desse movimento.

Isso foi antes da virada de ano, no fim de dezembro de 2016. Tivemos umas pequenas férias, e me lembro de que passei o tempo inteiro escrevendo o texto, e realmente, naquele momento, fiz questão de me atirar em um território de absoluto desconhecido, como se precisasse encontrar novamente os fundamentos dessa peça que eu tinha abdicado de saber qual era. Foi nessa busca que Branco se formou e, se isso se deu em um mergulho 
absolutamente radical nas minhas mais profundas fantasias, paranoias e medos pessoais - não para a partir desse universo falar de algo, ou dar conta de determinados assuntos ou posições; mas, ao contrário, para, a partir desse mergulho, não dar conta de nada, mas simplesmente fazer com que as dinâmicas, os horrores, os fantasmas viessem à tona para então dissolvê-los.

Se pensarmos com Walter Benjamin, ou com Agamben, creio que essa última reescrita do texto foi precisamente aquela que teve a capacidade de mergulhar no universo dos meios puros. Expulsou-se ali qualquer finalidade. A radicalidade de reescrever tudo, mas (ao contrário do que aconteceu na segunda versão da peça) não tentar dar conta de nada por meio da escrita, mas, sim, abrir espaço para que ela trouxesse à tona tudo o que estava submerso, debaixo das nossas certezas, dúvidas e opiniões, tal radicalidade era, justamente, a radicalidade de expulsar do processo toda e qualquer finalidade que pudesse querer se impor.

De fato, tal tipo de trabalho se aproxima muito do que Agamben denomina como profanação. Com efeito, a profanação, para Agamben, não é simplesmente uma retomada do objeto que foi capturado e sacralizado, que o traria de volta ao seu uso comum por parte dos homens. Mais complexo do que isso, o movimento que Agamben procura caracterizar como profanação é a desativação daquela separação - que difere da sua simples anulação: "profanar significa abrir a possibilidade de uma forma especial de negligência [em oposição ao cuidado minucioso do relegere da religião], que ignora a separação, ou melhor, faz dela um uso particular" (AGAMBEN, 2007, p. 66, grifos nossos). Dessa forma, o gesto profanatório, mais do que uma perspectiva de voltar a unir aquilo que foi separado pela religião, é, antes, uma possibilidade de que façamos um outro uso dessa própria separação.

Ou seja, se a religião é a atitude cuidadosa, minuciosa, que tem por foco manter a separação, a profanação se caracteriza pela negligência diante dela. Ou ainda, por um tipo de negligência peculiar, que faz um outro uso da separação'. A certa altura Agamben usa o exemplo de um gato que brinca com um novelo de lã. $\mathrm{O}$ gato desativa o dispositivo genético da caça, da

1 "profanar significa abrir a possibilidade de uma forma especial de negligência, que ignora a separação, ou melhor, faz dela um uso particular” (AGAMBEN, 2007, p. 66). 
captura, ao atacar uma bola de lã ao invés de um rato. Os comportamentos predatórios do gato (que têm uma finalidade particular) são, dessa forma, arrancados a esse fim, e libertados para outros usos - transformando-se, assim, por meio de uma espécie de brincadeira, ou de jogo, em meios puros ${ }^{2}$.

Mas isso, esse movimento aparentemente irresponsável (mas que em nenhum momento perde contato com a profundidade daquilo que opera), que propõe uma atitude de jogo a partir de materiais profundos, já foi feito em um contato direto com aqueles que estavam já do lado de fora, aguardando pelo que sairia de tais profundezas - que já não eram apenas minhas, mas deles também.

\section{Referências bibliográficas}

AGAMBEN, G. Profanações. São Paulo: Boitempo, 2007.

BENJAMIN, W. Escritos sobre mito e linguagem. São Paulo: Editora 34, 2011.

Recebido em 18/10/2017

Aprovado em 23/10/2017

Publicado em 26/12/2017

2 A propósito, a ideia de violência divina, abordada por Benjamin no texto Para uma crítica da violência, também se caracteriza sobretudo pelo fato de que ela não tenha uma finalidade externa a si mesma. A violência divina é, ela mesma, também um meio sem fim sendo este um dos pontos de contato entre essa ideia e o conceito de profanação: "A violência divina, que é insígnia e selo, nunca meio de execução sagrada, pode ser chamada de "violência que reina"' (BENJAMIN, 2011, p. 156, grifos nossos). 


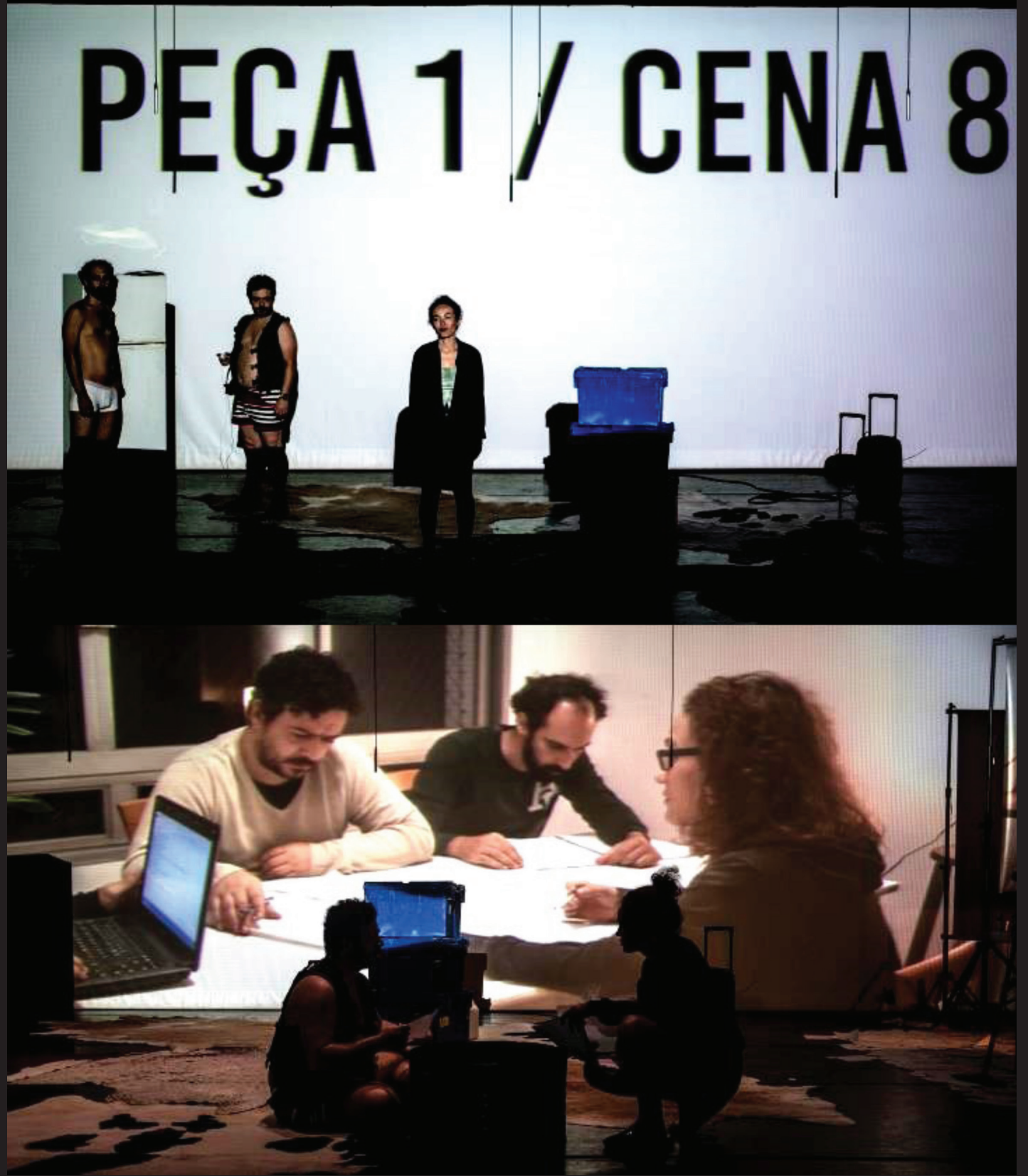




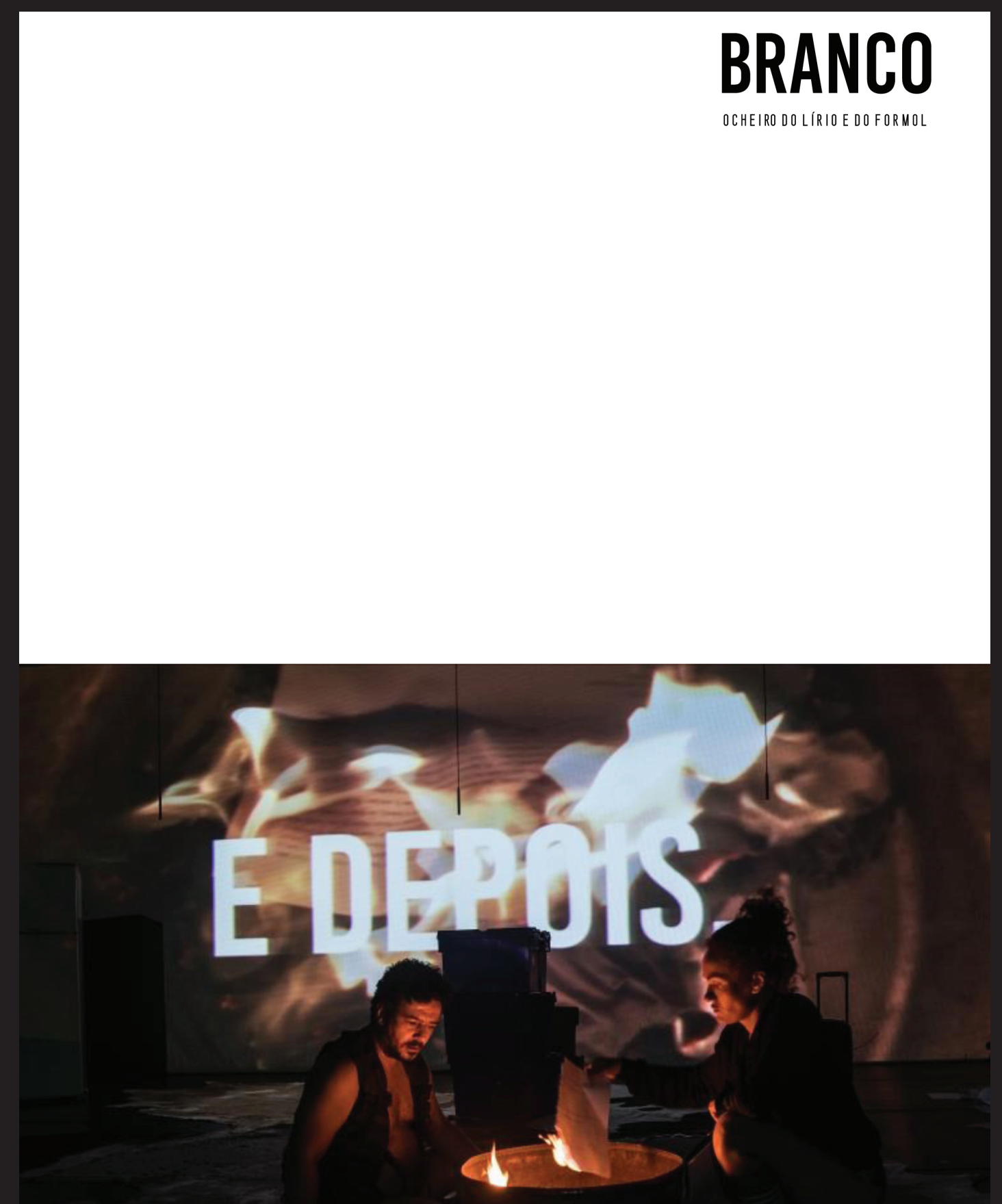




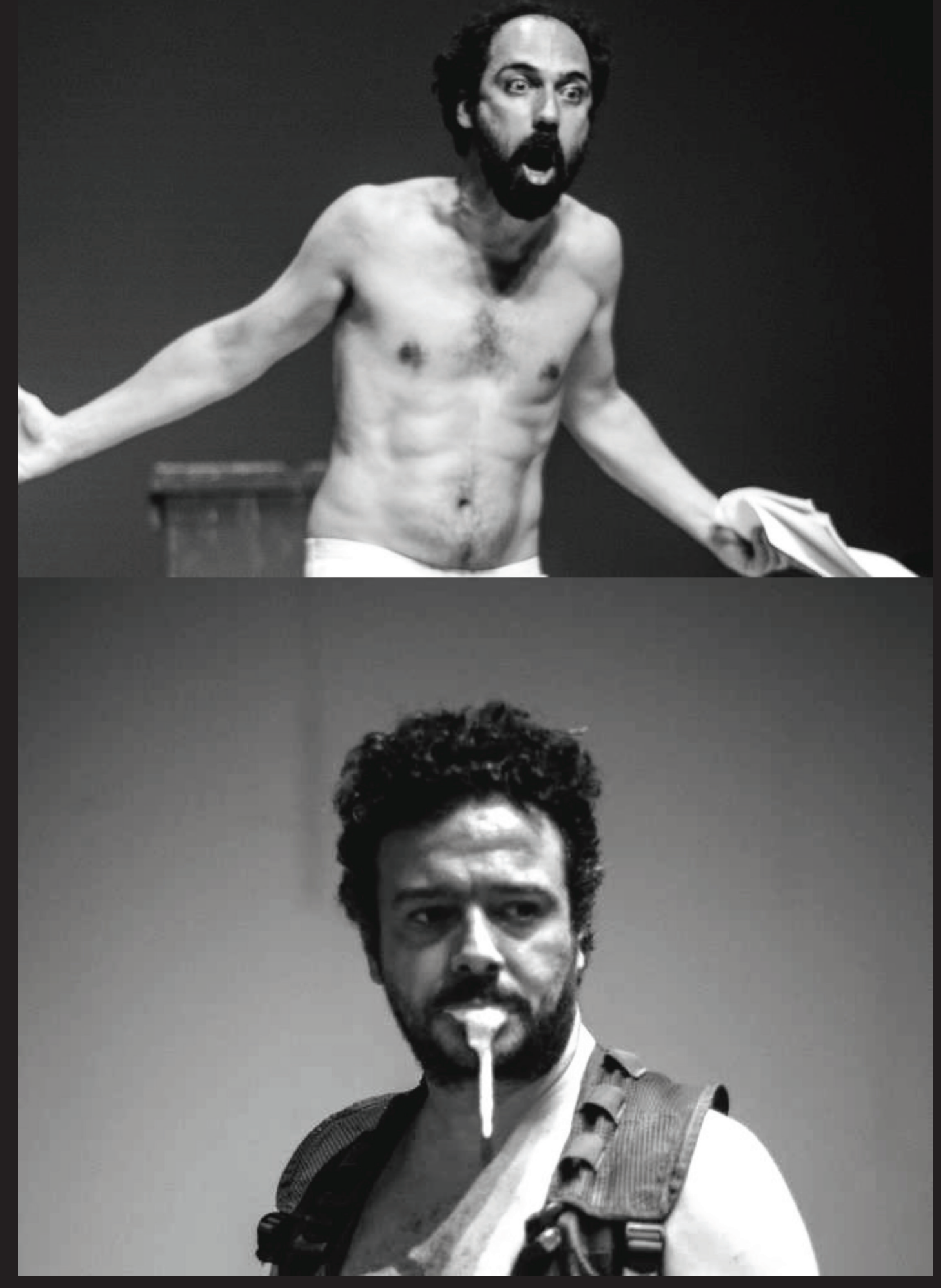



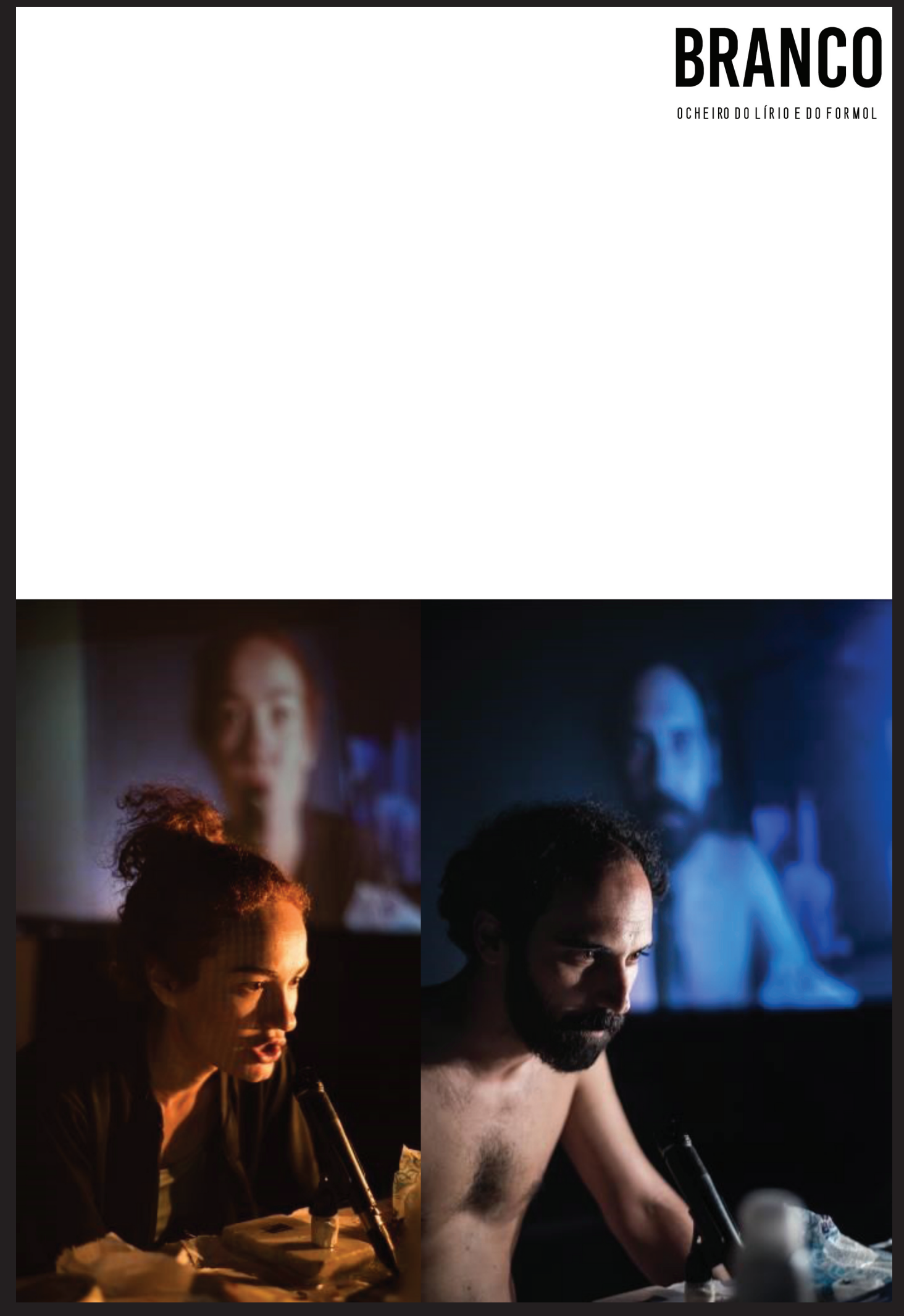


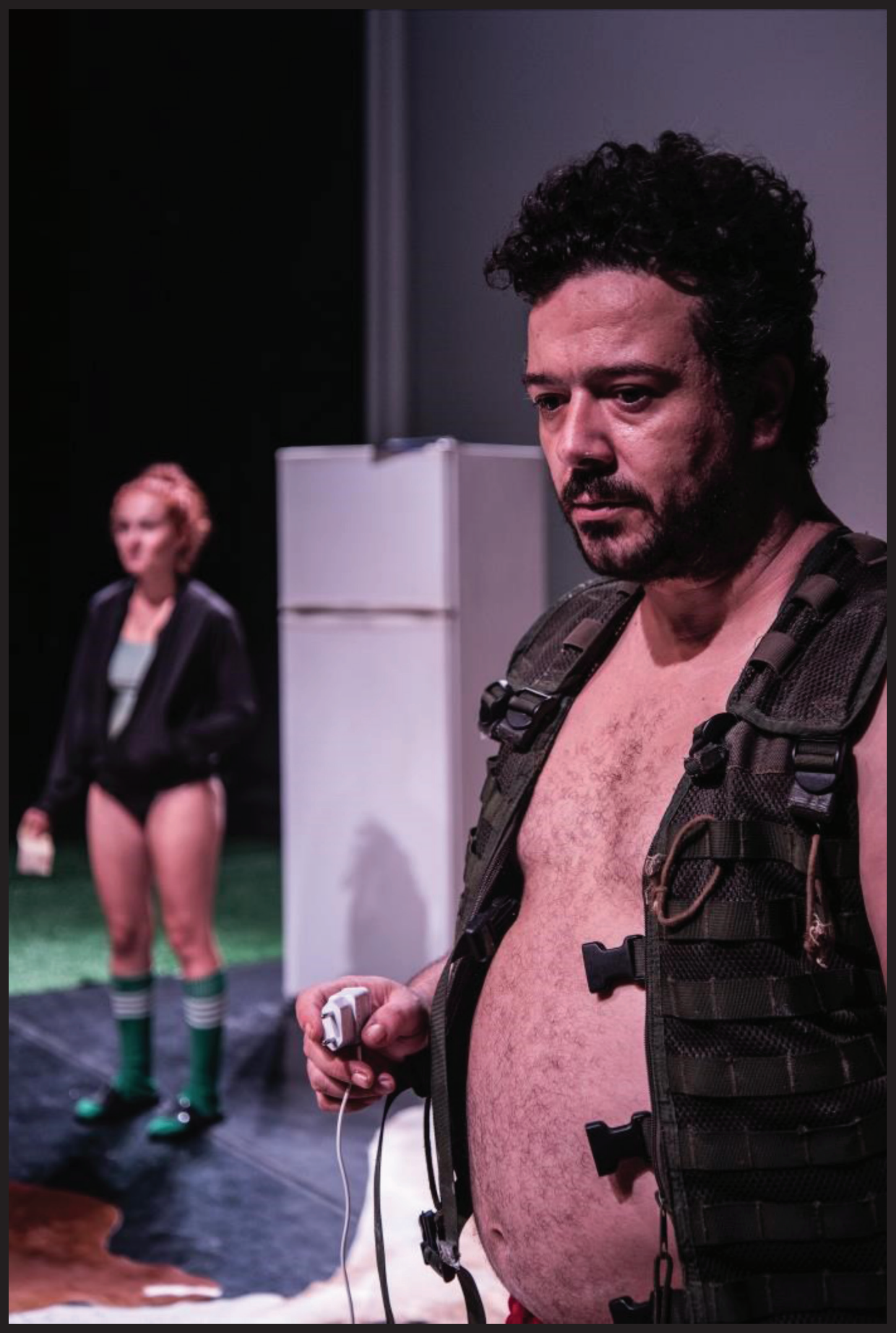




\title{
BRANCO
}

\author{
OCHEIRODOLÍRIOEDOFORMOL
}

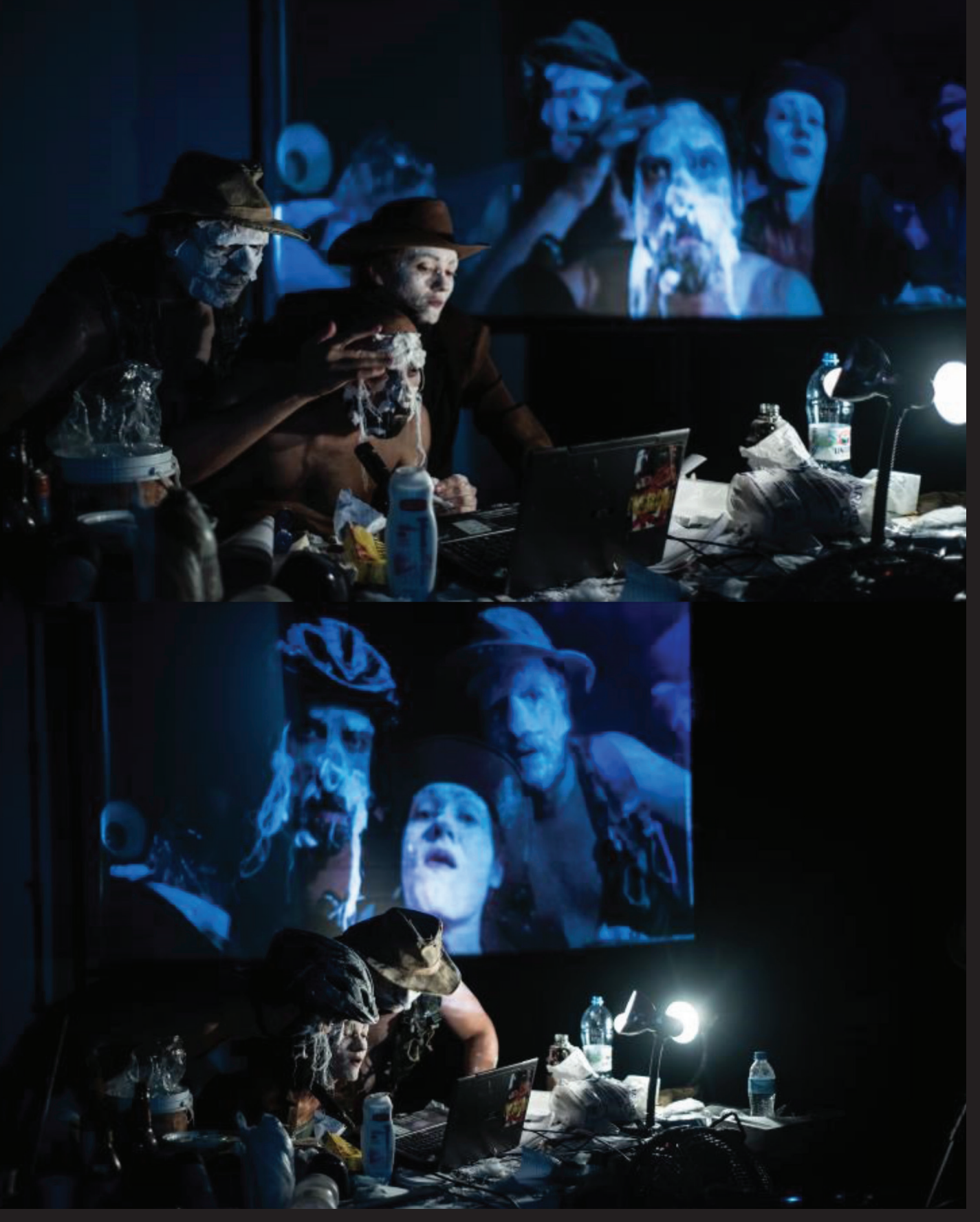



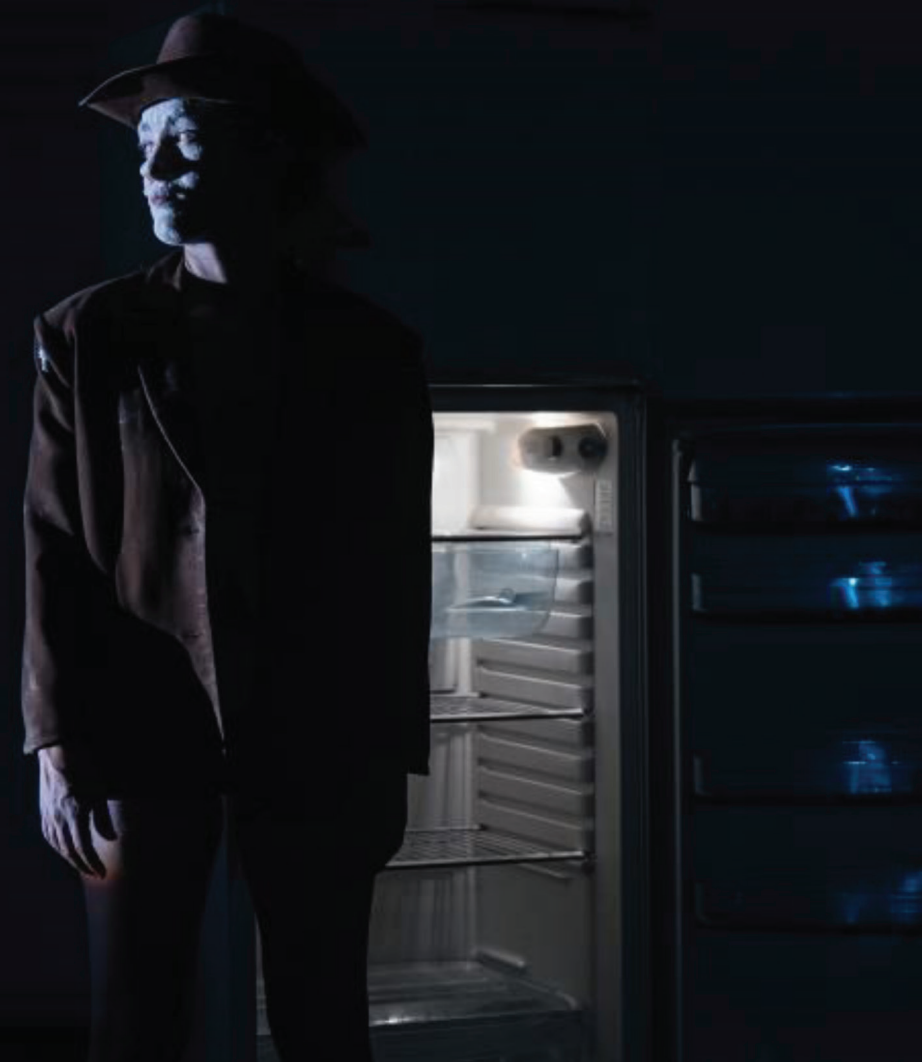

BRANCO 